\title{
Short communication: Oxidative status and incidence of mastitis relative to blood $\alpha$-tocopherol concentrations in the postpartum period in dairy cows
}

\author{
I. Politis, ${ }^{\star 1}$ G. Theodorou, ${ }^{*}$ A. D. Lampidonis, ${ }^{*}$ A. Kominakis, ${ }^{*}$ and A. Baldi† \\ *Department of Animal Science and Aquaculture, Agricultural University of Athens, 11855 Athens, Greece \\ †Department of Veterinary Science and Technology for Food Safety, University of Milan, 20133 Milan, Italy
}

\begin{abstract}
Vitamin E supplementation, when combined with high blood $\alpha$-tocopherol $(>6.25 \mu \mathrm{g} / \mathrm{mL})$ at dry off, has been reported to unexpectedly increased the risk for clinical mastitis in dairy cows. Furthermore, higher levels of oxidative stress in the postpartum period were related to higher risk of mastitis. The objective of the present study was to determine the relationship between various serum biomarkers of oxidative status, incidence of mastitis, and blood $\alpha$-tocopherol concentrations at dry off and at calving. A total of 146 dairy cows from a commercial farm were used in an observational field study. All cows were supplemented with 3,000 and 500 $\mathrm{IU} /$ cow per day of all-rac- $\alpha$-tocopherol during the dry period and lactation, respectively. Blood samples were collected at dry off and at calving. Serum was analyzed for $\alpha$-tocopherol, levels of reactive oxygen metabolites (ROM), thiol groups (SH), and ferric-reducing ability. Three $\alpha$-tocopherol groups at calving were created: high $(>3 \mu \mathrm{g} / \mathrm{mL})$, medium $(2-3 \mu \mathrm{g} / \mathrm{mL})$, and low $(<2$ $\mu \mathrm{g} / \mathrm{mL})$. Three $\alpha$-tocopherol groups at dry off were created: high $(>6.25 \mu \mathrm{g} / \mathrm{mL})$, medium $(4.25-6.25 \mu \mathrm{g} / \mathrm{mL})$, and low $(<4.25 \mu \mathrm{g} / \mathrm{mL})$. All cases of clinical mastitis that occurred during the dry period and the entire subsequent lactation were verified by a veterinarian. No differences were observed in the incidence of mastitis between the $3 \alpha$-tocopherol groups based on the serum levels at dry off. Incidence of mastitis was 4 times lower in the high and medium groups when compared with the corresponding value for the low- $\alpha$-tocopherol group based on the serum levels at calving. Lower levels of ROM and SH at dry off and at calving were found in the group of cows with the highest $\alpha$-tocopherol values at dry off when compared with the corresponding values in the low- $\alpha$-tocopherol group. The ROM values at dry off but not at calving were lower in the group of cows with the highest $\alpha$-tocopherol values at calving when compared with the corresponding values
\end{abstract}

Received June 22, 2012.

Accepted September 4, 2012.

${ }^{1}$ Corresponding author: i.politis@aua.gr in the low- $\alpha$-tocopherol group. No differences were observed in ferric-reducing ability values between the $3 \alpha$-tocopherol groups at dry off or calving. No differences were observed in all biomarkers of oxidative status between healthy cows and those with mastitis. Thus, blood $\alpha$-tocopherol is inversely related to certain biomarkers of oxidative stress in the postpartum period and incidence of mastitis. However, reduction in the incidence of mastitis is not mediated through a reduction in the levels of various biomarkers of oxidative stress.

Key words: $\alpha$-tocopherol, oxidative stress, incidence of mastitis

\section{Short Communication}

Oxidative stress in a living organism is generated when free radical production exceeds the capacity of the antioxidant mechanisms. The majority of the evidence suggests that dairy cows experience oxidative stress during the periparturient period (Brzezinska-Slebodzinska et al., 1994; Bernabucci et al., 2005; Castillo et al., 2005, 2006; Bouwstra et al., 2008, 2009). Bernabucci et al. (2005) reported that dairy cows with higher BCS and higher body condition losses are more prone to oxidative stress during the periparturient period. Castillo et al. (2005) reported that lipid peroxidation increased around parturition. Dairy heifers also appear to experience oxidative stress at calving (Bouwstra et al., 2008). Even though it has been hypothesized that increased oxidative stress is the etiology of various diseases and disorders including mastitis, the actual evidence in the case of mastitis is limited.

Vitamin $\mathrm{E}$ is one of the main antioxidant vitamins in dairy cows. It has been reported that vitamin E supplementation of dairy cows with $3,000 \mathrm{IU} /$ cow per day during the dry period, when combined with high levels of blood $\alpha$-tocopherol at dry off $(>6.25 \mu \mathrm{g} / \mathrm{mL})$, unexpectedly increased the incidence of mastitis (Bouwstra et al., 2010b). In a follow-up paper, Bouwstra et al. (2010a) reported that higher levels of oxidative stress in vitamin E-supplemented cows at wk 2 antepartum were related to higher risk of developing clinical mastitis. They suggested that supplementation of dairy cows 
with vitamin E could possibly overload the oxidative cascade and this could provide an explanation for the unexpected adverse effects observed in terms of clinical mastitis. The data of the 2 studies mentioned above led the authors to question the supplementation of dairy cows with vitamin $\mathrm{E}$ at the rate of $3,000 \mathrm{IU} /$ cow per day during the dry period. However, 2 previous studies from the same research group reported slightly different results. In the first study, Bouwstra et al. (2008) reported lower levels of oxidative stress at wk 2 after calving in vitamin E-supplemented cows compared with the corresponding values in control cows. These findings led the authors to suggest that vitamin $\mathrm{E}$ may speed up the recovery from parturition-related oxidative stress. In the second study, Bouwstra et al. (2008) reported that vitamin E supplementation $(1,000 \mathrm{IU} /$ cow per day) reduces MDA serum levels in dairy cows. Very recently, Politis (2012) reported that high blood $\alpha$-tocopherol values at dry off do not constitute a risk factor for developing mastitis, which is the opposite from findings of Bouwstra et al. (2010b). The study of Politis (2012) did not deal with the issue of the oxidative stress.

Because limited studies exist that have actually measured changes in various peroxidative markers in vitamin E-supplemented cows in the postpartum period, the objectives of the present study were (1) to determine the relationship between incidence of clinical mastitis and blood $\alpha$-tocopherol levels at dry off and at calving, (2) to examine the relationship between various peroxidative biomarkers and blood $\alpha$-tocopherol levels at dry off and at calving in dairy cows, and (3) to determine whether differences occur in various biomarkers of oxidative stress between healthy cows and those with mastitis.

One hundred forty-six cows from a commercial farm located in the Northern part of Greece participated in an observational field study. All cows were supplemented with all-rac- $\alpha$-tocopherol at the rate of 3,000 and $500 \mathrm{IU} /$ cow per day during the dry period and lactation, respectively. Blood samples from the same cows were collected exactly at the day of drying off and again at calving. Serum was obtained following centrifugation of the blood samples $(820 \times g$ for $10 \mathrm{~min}$ at $4^{\circ} \mathrm{C}$ ) and was frozen at $-80^{\circ} \mathrm{C}$ until analysis. Serum was analyzed for $\alpha$-tocopherol (Politis et al., 2004); levels of reactive oxygen metabolites (ROM) using the spectrophotometric method, which uses the chromogenic substrate $N, N$-dimethyl- $p$-phenylendiamine (Verde et al., 2002); thiol groups (SH) by the spectrophotometric method suggested by Bernabucci et al. (2005); and ferric-reducing ability (FRA) using the method of Benzie and Strain (1996). Veterinary-verified (treated or not for milder systemic symptoms) cases of clinical mastitis were recorded. Mastitis was originally identified by the herdsman based on the occurrence of gross swelling, heat, redness, pain, disturbed function characterized by a decrease in milk production, or changes in milk composition. Milk production for each individual cow was recorded daily and data on milk composition were available weekly. Furthermore, the cows were examined for systemic symptoms (fever, depression, shivering, loss of appetite, and loss of weight) or lesser systemic symptoms (fever or milder depression). Last, the milk was checked for watery appearance and the presence of clots. All cases of clinical mastitis (whether treated or not) were verified within the same day by a veterinarian. Milder cases of mastitis that occurred during middle and late lactation were left untreated but they were still recorded. Cows were observed for the occurrence of clinical mastitis throughout the dry period and the entire subsequent lactation. A cow was only once classified as having mastitis, independent of how many quarters were mastitic or whether relapsing of the infection took place.

A $2 \times 3$ contingency table analysis and the chisquared test were applied to test for differences in the incidence of mastitis between the 3 subclasses (groups) of $\alpha$-tocopherol values at calving and another 3 subclasses (groups) of $\alpha$-tocopherol at dry off. The 3 $\alpha$-tocopherol subclasses at calving were the following: high $(>3 \mu \mathrm{g} / \mathrm{mL})$, medium $(2-3 \mu \mathrm{g} / \mathrm{mL})$, and low $(<2$ $\mu \mathrm{g} / \mathrm{mL}$ ). The $3 \alpha$-tocopherol subclasses at dry off were the following: high $(>6.25 \mu \mathrm{g} / \mathrm{mL})$, medium $(4.25-6.25$ $\mu \mathrm{g} / \mathrm{mL})$, and low $(<4.25 \mu \mathrm{g} / \mathrm{mL})$.

Two multivariate ANOVA (MANOVA), fitting the $\alpha$-tocopherol subclasses and sampling time as the fixed effects, were used to test for differences in markers of oxidative stress (ROM, SH, and FRA) values between the $3 \alpha$-tocopherol subclasses at dry off and at calving and for performing comparisons between the 2 sampling periods. Values in the tables are least squares means (with SE). The Bonferroni test was used for the $P$-values when performing multiple comparisons. A MANOVA fitting the health status with 2 subclasses (healthy and mastitic) as the fixed effect was used to test for differences in markers of oxidative stress (ROM, SH, and FRA) and blood $\alpha$-tocopherol values between healthy and cows with mastitis. All MANOVA were carried out using PROC GLM in SAS (version 9.0; SAS Institute, 2004).

Table 1 shows the relationship between frequency of clinical mastitis and blood $\alpha$-tocopherol levels at dry off and calving. No differences were observed in the incidence of mastitis between the $3 \alpha$-tocopherol groups at dry off. Furthermore, the incidence of masti- 
Table 1. Comparison of veterinary-confirmed cases of clinical mastitis relative to blood $\alpha$-tocopherol levels at dry off and calving in dairy cows supplemented with 3,000 and $500 \mathrm{IU}$ of vitamin E/cow per day during the dry period and lactation, respectively

\begin{tabular}{|c|c|c|c|c|c|c|c|c|}
\hline Period & $\begin{array}{c}\alpha \text {-Tocopherol } \\
\operatorname{group}(\mu \mathrm{g} / \mathrm{mL})\end{array}$ & \multicolumn{4}{|c|}{$\alpha$-Tocopherol ${ }^{1}(\mu \mathrm{g} / \mathrm{mL})$} & \multicolumn{2}{|c|}{ Number of cows } & $\chi^{2}(P$-value $)$ \\
\hline \multirow{2}{*}{ Dry off } & $4.25-6.25$ & 5.1 & 4.9 & 4.3 & 6.2 & 63 & 14 & \multirow{2}{*}{$1.47(0.48)$} \\
\hline & $<4.25$ & 3.6 & 3.7 & 2.8 & 4.1 & 27 & 8 & \\
\hline \multirow[t]{2}{*}{ Calving } & $>3$ & 4.0 & 3.8 & 3.2 & 5.2 & 37 & 4 & \multirow[b]{2}{*}{$19.70(<0.001)$} \\
\hline & $2-3$ & 2.5 & 2.6 & 2.0 & 3.0 & 57 & 5 & \\
\hline
\end{tabular}

${ }^{1} \mathrm{P} 10=10$ th percentile; P90 $=$ 90th percentile.

tis (percentage of cows with mastitis versus those that remain healthy) was 4 times lower in the high- $(>3 \mu \mathrm{g} /$ $\mathrm{mL})$ and medium- $(2-3 \mu \mathrm{g} / \mathrm{mL}) \alpha$-tocopherol groups compared with the corresponding value for the low$\alpha$-tocopherol group $(<2 \mu \mathrm{g} / \mathrm{mL})$ based on the serum levels at calving.

Table 2 shows the relationship between serum ROM values relative to $\alpha$-tocopherol levels at dry off and calving. Lower levels of ROM at dry off and at calving were found in the group of cows with the highest $\alpha$-tocopherol values at dry off $(>6.25 \mu \mathrm{g} /$ $\mathrm{mL})$ compared with the corresponding values in the medium $(4.25-6.25 \mu \mathrm{g} / \mathrm{mL})$ and low $(<4.25 \mu \mathrm{g} / \mathrm{mL})$ $\alpha$ - tocopherol groups. Lower levels of ROM at dry off but not at calving were found in the group of cows with the highest $\alpha$-tocopherol values at calving $(>3$ $\mu \mathrm{g} / \mathrm{mL}$ ) compared with the corresponding values in the low- $(<2 \mu \mathrm{g} / \mathrm{mL}) \alpha$-tocopherol group. The mean ROM value for all $\alpha$-tocopherol groups at calving was higher than the corresponding value at dry off.

Table 3 shows the relationship between serum $\mathrm{SH}$ values relative to $\alpha$-tocopherol levels at dry off and calving. Lower levels of SH were found in the group of cows with the highest vitamin E values at dry off $(>6.25 \mu \mathrm{g} / \mathrm{mL})$ compared with the corresponding val- ues in the low- $(<4.25 \mu \mathrm{g} / \mathrm{mL}) \alpha$-tocopherol group. In contrast, no differences were observed in the SH levels at dry off and at calving between the $3 \alpha$-tocopherol groups based on the serum levels at calving. The mean SH value for all $\alpha$-tocopherol groups at calving was higher than the corresponding value at dry off.

No differences were observed in the FRA levels at dry off or calving between the high, medium, or low $\alpha$-tocopherol groups at dry off or calving. Furthermore, no differences existed between FRA values between calving and dry off (data not shown).

Table 4 allows a comparison of $\alpha$-tocopherol levels, and antioxidant parameters (ROM, SH, and FRA) between healthy and mastitic cows. Cows with mastitis had lower concentration of $\alpha$-tocopherol than healthy cows. No differences existed in all antioxidant parameters measured (ROM, SH, and FRA) in cows with mastitis compared with those that remain healthy.

The first finding emerging from the present study is that low levels $(<2 \mu \mathrm{g} / \mathrm{m})$ of blood $\alpha$-tocopherol levels at calving are associated with increased incidence of mastitis. These data are very similar with those of Weiss et al. (1997) who reported that cows with blood

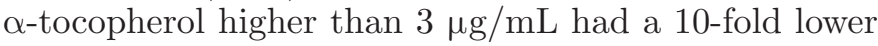
probability of developing mastitis than cows with the

Table 2. Comparison of reactive oxygen metabolites (ROM) relative to blood $\alpha$-tocopherol levels at dry off and at calving in dairy cows supplemented with 3,000 and $500 \mathrm{IU}$ of vitamin E/cow per day during the dry period and lactation, respectively

\begin{tabular}{lcccc}
\hline Period & $\begin{array}{c}\alpha \text {-Tocopherol } \\
\text { group }(\mu \mathrm{g} / \mathrm{mL})\end{array}$ & $\begin{array}{c}\text { ROM at } \\
\text { dry-off }(\mathrm{U} / \mathrm{mL})\end{array}$ & $\begin{array}{c}\text { ROM at } \\
\text { calving }(\mathrm{U} / \mathrm{mL})\end{array}$ & $\begin{array}{c}\text { Probability } \\
\text { within rows }\end{array}$ \\
\hline Dry off & $>6.25$ & $40.8 \pm 3.2^{\mathrm{a}}$ & $49.6 \pm 3.2^{\mathrm{a}}$ & NS \\
& $4.25-6.25$ & $53.3 \pm 2.1^{\mathrm{b}}$ & $61.1 \pm 2.1^{\mathrm{b}}$ & NS \\
Calving & $<4.25$ & $56.2 \pm 3.1^{\mathrm{b}}$ & $64.4 \pm 3.1^{\mathrm{b}}$ & NS \\
& Mean & $50.0 \pm 1.6$ & $58.4 \pm 1.6$ & $<0.001$ \\
& $2-3$ & $41.5 \pm 2.9^{\mathrm{a}}$ & $53.0 \pm 2.9$ & NS \\
& $<2$ & $51.5 \pm 2.5^{\mathrm{ab}}$ & $61.2 \pm 2.5$ & NS \\
& $2-3.3 \pm 2.6^{\mathrm{b}}$ & $62.0 \pm 2.6$ & NS \\
& Mean & $50.4 \pm 1.5$ & $58.7 \pm 1.5$ & $<0.001$ \\
\hline
\end{tabular}

${ }_{\mathrm{a}, \mathrm{b}}$ Means within the same column and period followed by different letters differ at $P<0.05$.

${ }^{1}$ All values are $\mathrm{LSM} \pm \mathrm{SEM}$. 
Table 3. Comparison of thiol groups (SH) relative to blood $\alpha$-tocopherol levels at dry off and at calving in dairy cows supplemented with 3,000 and $500 \mathrm{IU}$ of vitamin E/cow per day during the dry period and lactation, respectively $^{1}$

\begin{tabular}{lcccc}
\hline Period & $\begin{array}{c}\alpha \text {-Tocopherol } \\
\text { group }(\mu \mathrm{g} / \mathrm{mL})\end{array}$ & $\begin{array}{c}\text { SH at dry } \\
\text { off }(\mu \mathrm{mol} / \mathrm{L})\end{array}$ & $\begin{array}{c}\text { SH at calving } \\
(\mu \mathrm{mol} / \mathrm{L})\end{array}$ & $\begin{array}{c}\text { Probability } \\
\text { within rows }\end{array}$ \\
\hline Dry off & $>6.25$ & $319 \pm 26^{\mathrm{a}}$ & $417 \pm 26^{\mathrm{a}}$ & NS \\
& $4.25-6.25$ & $378 \pm 17^{\mathrm{ab}}$ & $445 \pm 17^{\mathrm{a}}$ & NS \\
Calving & $<4.25$ & $402 \pm 25^{\mathrm{b}}$ & $513 \pm 26^{\mathrm{b}}$ & $<0.05$ \\
& Mean & $366 \pm 14$ & $458 \pm 14$ & $<0.001$ \\
& $>3$ & $345 \pm 24$ & $428 \pm 24$ & NS \\
& $2-3$ & $364 \pm 21$ & $440 \pm 21$ & NS \\
& $<2$ & $398 \pm 21$ & $492 \pm 22$ & $<0.05$ \\
& Mean & $369 \pm 13$ & $453 \pm 13$ & $<0.001$ \\
\hline
\end{tabular}

$\overline{\mathrm{a}, \mathrm{b}}$ Means within the same column and period followed by different letters differ at $P<0.05$.

${ }^{1}$ All values are $\operatorname{LSM} \pm \mathrm{SEM}$.

corresponding value lower than $3 \mu \mathrm{g} / \mathrm{mL}$. Furthermore, the data from the present study do not support the notion that high values of $\alpha$-tocopherol $(>6.25 \mu \mathrm{g} / \mathrm{mL})$ at dry off increase the risk for developing mastitis. Our data are consistent with those of Politis (2012) and are in disagreement with those of Bouwstra et al. (2010b). The reason for the difference that exists between our conclusions and those of Bouwstra et al. (2010b) are not known with certainty. Differences in the type and severity of mastitis, definition of mastitis, diets, and management could have contributed to the different results.

The second finding emerging from the present study is that high levels of $\alpha$-tocopherol in the postpartum period are associated with reduced levels of 2 key biomarkers of oxidative stress, namely ROM and SH. Our data show that $\alpha$-tocopherol is generally inversely related to 2 measures of oxidative stress ( $\mathrm{SH}$ and $\mathrm{ROM}$ ). Our conclusions are very different from those of Bouwstra et al. (2010a) who suggested that high $\alpha$-tocopherol

Table 4. Effect of health status on $\alpha$-tocopherol, reactive oxygen metabolites (ROM), thiol groups ( $\mathrm{SH})$, and ferric-reducing ability (FRA) in blood serum at dry off and at calving in dairy cows supplemented with 3,000 and $500 \mathrm{IU}$ of vitamin E/cow per day during the dry period and lactation, respectively ${ }^{1}$

\begin{tabular}{lcc}
\hline & \multicolumn{2}{c}{ Health status } \\
\cline { 2 - 3 } Parameter & Healthy & Mastitic \\
\hline$\alpha$-Tocopherol at dry off $(\mu \mathrm{g} / \mathrm{mL})$ & $5.32 \pm 0.13$ & $4.86 \pm 0.28$ \\
$\alpha$-Tocopherol at calving $(\mu \mathrm{g} / \mathrm{mL})$ & $2.74 \pm 0.1^{\mathrm{a}}$ & $1.9 \pm 0.23^{\mathrm{b}}$ \\
ROM at dry off $(\mathrm{U} / \mathrm{mL})$ & $50.5 \pm 1.7$ & $53.6 \pm 3.7$ \\
ROM at calving $(\mathrm{U} / \mathrm{mL})$ & $59.6 \pm 1.8$ & $57.5 \pm 3.9$ \\
SH at dry off $(\mu \mathrm{mol} / \mathrm{L})$ & $372 \pm 14$ & $364 \pm 30$ \\
SH at calving $(\mu \mathrm{mol} / \mathrm{L})$ & $459 \pm 14$ & $435 \pm 31$ \\
FRA at dry off $(\mu \mathrm{mol} / \mathrm{L})$ & $263 \pm 12$ & $229 \pm 25$ \\
FRA at calving $(\mu \mathrm{mol} / \mathrm{L})$ & $229 \pm 10$ & $208 \pm 22$ \\
\hline
\end{tabular}

${ }^{\mathrm{a}, \mathrm{b}}$ Means within the same row followed by different letters differ at $P$ $<0.05$.

${ }^{1}$ All values are $\mathrm{LSM} \pm \mathrm{SEM}$. increased oxidative stress in certain cows. Furthermore, they suggested that $\alpha$-tocopherol might show its beneficial effects only in cows that start supplementation with a deficient or marginal vitamin E status. The reason that these differences occur were explained in the previous paragraph.

The third finding emerging from the present study is that the beneficial effects of high $\alpha$-tocopherol levels in the postpartum period in terms of reduced incidence of mastitis are not mediated through a reduction in the levels of certain biomarkers of oxidative stress. This conclusion is supported by our data showing no differences in all biomarkers of oxidative stress between healthy and cows with mastitis. Thus, the most reasonable explanation for the reduced incidence of mastitis observed in cows with high $\alpha$-tocopherol levels in the postpartum period is that high $\alpha$-tocopherol reduces the risk for developing mastitis by improving immune competency, as suggested by Politis (2012) in a study from the same database. The present study suggests that oxidative stress increases around parturition. This conclusion is supported by our data showing increases in both $\mathrm{ROM}$ and $\mathrm{SH}$ values at calving compared with the corresponding values at dry off. These data are similar to those of Bernabucci et al. (2005) and Castillo et al. (2005).

In conclusion, the present study documents that high blood $\alpha$-tocopherol values in the postpartum period are generally associated with reduced levels of certain biomarkers of oxidative stress and reduced incidence of mastitis. However, reduction in the incidence of mastitis is not mediated through a reduction in the levels of various biomarkers of oxidative stress.

\section{ACKNOWLEDGMENTS}

This study was financially supported by DSM Nutritional Products AG (Kaiseraugst, Switzerland). 


\section{REFERENCES}

Benzie, I. F., and J. J. Strain. 1996. The ferric reducing ability of plasma (FRAP) as a measure of "antioxidant power": The FRAP assay. Anal. Biochem. 239:70-76.

Bernabucci, U., B. Ronchi, N. Lacetera, and A. Nardone. 2005. Influence of body condition score on relationships between metabolic status and oxidative stress in periparturient dairy cows. J. Dairy Sci. 88:2017-2026.

Bouwstra, R. J., R. M. Goselink, P. Dobbelaar, M. Nielen, J. R. Newbold, and T. van Werven. 2008. The relationship between oxidative damage and vitamin $\mathrm{E}$ concentration in blood, milk, and liver tissue from vitamin E supplemented and nonsupplemented periparturient heifers. J. Dairy Sci. 91:977-987.

Bouwstra, R. J., M. Nielen, J. R. Newbold, E. H. Jansen, H. F. Jelinek, and T. van Werven. 2010a. Vitamin E supplementation during the dry period in dairy cattle. Part II: Oxidative stress following vitamin E supplementation may increase clinical mastitis incidence postpartum. J. Dairy Sci. 93:5696-5706.

Bouwstra, R. J., M. Nielen, J. A. Stegeman, P. Dobbelaar, J. R. Newbold, E. H. Jansen, and T. van Werven. 2010b. Vitamin E supplementation during the dry period in dairy cattle. Part I: Adverse effect on incidence of mastitis postpartum in a double-blind randomized field trial. J. Dairy Sci. 93:5684-5695.

Bouwstra, R. J., M. Nielen, and T. van Werven. 2009. Comparison of the oxidative status of vitamin E-supplemented and non-supplemented cows under field conditions. Tijdschr. Diergeneeskd. 134:656-661
Brzezinska-Slebodzinska, E., J. K. Miller, J. D. Quigley III, J. R. Moore, and F. C. Madsen. 1994. Antioxidant status of dairy cows supplemented prepartum with vitamin E and selenium. J. Dairy Sci. $77: 3087-3095$.

Castillo, C., J. Hernandez, A. Bravo, M. Lopez-Alonso, V. Pereira, and J. L. Benedito. 2005. Oxidative status during late pregnancy and early lactation in dairy cows. Vet. J. 169:286-292.

Castillo, C., J. Hernández, I. Valverde, V. Pereira, J. Sotillo, M. L. Alonso, and J. L. Benedito. 2006. Plasma malonaldehyde (MDA) and total antioxidant status (TAS) during lactation in dairy cows. Res. Vet. Sci. 80:133-139.

Politis, I. 2012. Reevaluation of vitamin E supplementation of dairy cows: Bioavailability, animal health and milk quality. Animal 6:1427-1434. http://dx.doi.org/10.1017/S1751731112000225.

Politis, I., I. Bizelis, A. Tsiaras, and A. Baldi. 2004. Effect of vitamin E supplementation on neutrophil function, milk composition and plasmin activity in dairy cows in a commercial herd. J. Dairy Res. $71: 273-278$.

SAS Institute. 2004. SAS/STAT Software Version 9.0 for Windows. SAS Inst. Inc., Cary, NC.

Verde, V., V. Fogliano, A. Ritieni, G. Maiani, F. Morisco, and N. Caporaso. 2002. Use of N,N-dimethyl-p-phenylenediamine to evaluate the oxidative status of human plasma. Free Radic. Res. $36: 869-873$.

Weiss, W. P., J. S. Hogan, D. A. Todhunter, and K. L. Smith. 1997. Effect of vitamin E supplementation in diets with a low concentration of selenium on mammary gland health of dairy cows. J. Dairy Sci. 80:1728-1737. 